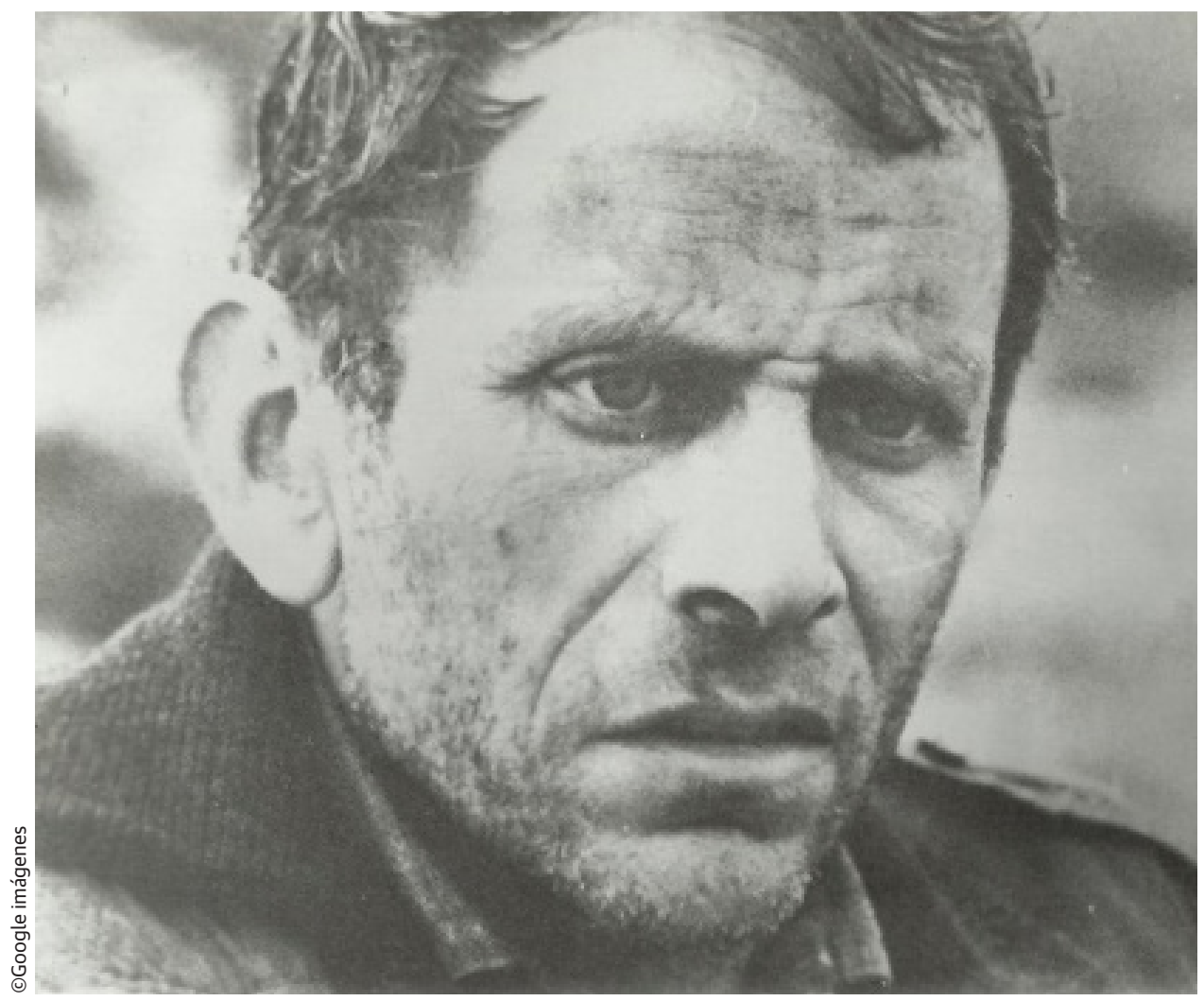

\title{
LA DIALÉCTICA REALIDAD/ FABULACIÓN EN EL DISCURSO FÍLMICO DE GUTIÉRREZ ARAGÓN
}

\author{
THE DIALECTIC \\ REALITY/INVENTIVENESS \\ IN THE DISCOURSE \\ OF GUTIERREZ ARAGON
}

José Luis Sánchez Noriega / noriega@ucm.es

UNIVERSIDAD COMPLUTENSE DE MADRID 


\section{RESUMEN}

En un estudio sobre el cine español de la Transición (1973-1984) desde la perspectiva de su capacidad para mostrar la historia y la realidad española contemporánea era indispensable profundizar en la figura del director Manuel Gutiérrez Aragón, pues es autor de algunas de las películas más significativas de ese período. A pesar de que de este cineasta se valora más la dimensión poética o metafórica de su lenguaje cinematográfico, teníamos la intuición de que su obra posee unas fuertes raíces en la sociedad española y en su historia desde la Guerra Civil. Nos interesaba poner en relación el realismo de estas raíces con la vertiente más poética o fabuladora de una filmografía siempre esquiva a las categorizaciones. A partir de un trabajo de análisis de cada una de las películas (Sánchez Noriega, ed., 2014) hemos realizado una aproximación transversal para indagar en las constantes de esta filmografía, constantes que se aprehenden mejor -a nuestro juicio- desde esta "dialéctica realidad / fabulación". A fin de mitigar la subjetividad inherente a un discurso de este tipo, además de nuestros análisis filmicos hemos tenido en cuenta ensayos de estudiosos y los propios testimonios del cineasta. Hay que subrayar como ejes de este discurso fílmico el realismo muy matizado por distorsiones que proporcionan al cine de Gutiérrez Aragón una notable cualidad poética; la memoria familiar desde la infancia y los espacios naturales vinculados a ella; la representación del marco social y político desde la España franquista de los cuarenta a las tensiones de la transición a la democracia; y la construcción de los personajes donde son relevantes la figura del traidor/ héroe y el tema de la adquisición del conocimiento y el adoctrinamiento.

PALABRAS CLAVE

Cine español, transición, Gutiérrez Aragón, franquismo, maquis, memoria familiar, adoctrinamiento

\section{ABSTRACT}

In an analysis about Spanish cinema of the Transition (1973-1984) from the perspective of its ability to show the history and the contemporary reality of Spain, it was essential to understand the figure of the director Manuel Gutierrez Aragon, him being the author of a few significant films of the period. Despite valuing, first and foremost, the poetic or metaphorical dimensions of his film language, we suspected that his work is deeply rooted in Spanish society and history since the Civil War. Thus, we were interested in establishing a link between these roots' realism and the more poetic, inventive side of a filmography always elusive to categorisations.

Starting from an analysis of each film (Sánchez Noriega, ed., 2014), we carried out a cross approximation to inquire about the constants of his filmography, constants that are better grasped - in our view - from this "dialectical reality / inventiveness". In order to mitigate the subjectivity inherent in our discourse, we have allowed for scholarly essays and the filmmaker's testimonies, in addition to our cinematic analyses.

The core ideas of this cinematic discourse include: a realism nuanced by distortions which add a poetic quality to Gutierrez Aragon's filmography; family memories since childhood and the natural spaces linked to them; the representation of the Spanish social and political situation, beginning in the Francoist forties and leading all the way into the tensions arising from the transition to democracy of the seventies; and the creation of characters when developing the figure of the traitor/hero and examining the acquisition of knowledge and persuasion.

KEYWORDS

Spanish cinema, Transition, Gutierrez Aragon, Francoism, Maquis, Family Memories, Indoctrination

Recibido: 10 de marzo de 2015

Aceptado: 5 de octubre de 2015 
"Personalmente creo que los límites de la realidad están mucho más lejos de lo que parece y reconozco que me tienta apurar la realidad hasta sus fronteras más extremas. En Maravillas conseguí llevar los límites del realismo mucho más lejos que en otras películas, pero sin salirme nunca de la realidad. Lo que se configuraba al final era una suma de distintas realidades, una especie de rea-

lidad reconstruida, surgida de la mezcla y adición de realidades muy diferentes y, a veces, hasta contradictorias entre sí. Quizá en esa fórmula reside, más que en ningún otro ejemplo, mi concepción del cine y de lo que debe ser el realismo." (Gutiérrez Aragón en F. Heredero, 1998b, 77).

\section{INTRODUCCIÓN}

La representatividad de las películas de Manuel Gutiérrez Aragón está fuera de duda en el conjunto de la historia del cine español y, en particular, del cine de la Transición ${ }^{1}$, período que coincide con sus primeros y más personales trabajos. Entre 1973 y 1986 filma nueve largometrajes², lo que constituye prácticamente la mitad de su obra cinematográfica, pues desde esa fecha hasta su renuncia al cine en 2008 para dedicarse a escribir ficción literaria rueda ocho películas. Naturalmente no hay que despreciar los cortos y mediometrajes, la docena de guiones para otros cineastas y los trabajos para televisión ${ }^{3}$; como tampoco sus artículos de prensa, puestas en escena teatrales y sus tres novelas (La vida antes de marzo, 2009; Gloria mía, 2012; y Cuando el frío llegue al corazón, 2013) que, en conjunto, revelan una personalidad creadora mucho más poliédrica de lo que parece a primera vista. Pero, en nuestra opinión, en esas películas de la primera parte de su carrera está en esencia y de modo muy completo este autor.

En las páginas que siguen nos planteamos indagar en las líneas de fuerza o ejes vertebradores de la filmografía de Gutiérrez Aragón de esa época, haciendo hincapié en las raíces, contextos, temas y estilemas que configuran un cine que, por otra parte, ha recibido una atención importante por los estudiosos y por la crítica, desde los ensayos más detenidos de Carlos F. Heredero o Molina Foix a trabajos académicos y numerosos artículos breves acerca de las películas concretas (vid. Bibliografía). A ello hay que añadir artículos de prensa de Gutiérrez Aragón -incluidas unas páginas de autobiografía escritas en $1982^{4}$-, su discurso de ingreso en la Academia de Bellas Artes de San Fernando (Gutiérrez Aragón, 2004), su ensayo sobre los actores, el cine y la memoria personal (Gutiérrez Aragón, 2015) que hemos comentado en otro lugar (Sánchez Noriega, 2015) y los testimonios del libro de conversaciones de Martínez Torres o el centenar de jugosas páginas del propio cineasta hablando sobre su concepción del cine y sobre sus películas concretas recogidas por F. Heredero (1998b).

\section{LA REALIDAD INSOBORNABLE Y SUS GRIETAS}

La característica más evidente del cine de Gutiérrez Aragón puede ser definida -siendo bien conscientes del esquematismo inherente a cualquier definición- como una relación dialógica entre la realidad más inmanente y documentada, impregnada de ambientes, espacios y objetos muy reconocibles, y su fabulación o ficcionalización a través de componentes mágicos o misteriosos que se muestran refractarios a la

\footnotetext{
1 Sobre el cine del período véase el capítulo "Trayectorias, libertades e identidades en el cine español (1974-1984)" en nuestro trabajo Sánchez Noriega (ed., 2014).

2 A saber, Habla, mudita (1973), Camada negra (1977)*, Sonámbulos (1978)*, El corazón del bosque (1978)*, Maravillas (1980)*, Demonios en el jardín (1982)*, Feroz (1984), La noche más hermosa (1984) y La mitad del cielo (1986). De las señaladas con asterisco hay un breve análisis individual en Sánchez Noriega (ed., 2014).

3 Están las prácticas de la Escuela Oficial de Cine Clara (1965), El vampiro de la Cava Baja (1966), Nana para dormir a un héroe (1967) y Hansel y Gretel (1969); el corto profesional El último día de la humanidad (1969) y el prólogo "Prueba de niños" del filme colectivo Cuentos para una escapada (1979), y los documentales El Cordobés (1970) y Semana Santa (1992). Pero lo más sobresaliente es la serie en cinco capítulos El Quijote (1991), adaptación de la primera parte de la novela cervantina, sobre la que hemos escrito en otro lugar (Sánchez Noriega, 2005).

4 "Autobiografía. El cine como tiempo", Triunfo, no 17, marzo 1982, pp. 56-61.
} 
racionalidad lógica. Esa realidad se presenta en dos dimensiones: una más personal, sensorial y directa que se nutre de colores, olores, sonidos y sabores de la infancia del cineasta, de ahí el fuerte protagonismo de los espacios y fenómenos naturales (bosques, prados, lluvia), los animales domésticos (vacas lecheras, perros) o salvajes cuyo ruido les hace más próximos, de manera que son películas transidas por la experiencia muy sensorial de una realidad manifiestamente insobornable. Y otra dimensión más generacional e histórica, de una realidad que tiene en cuenta el contexto político y el debate ético.

En la reivindicación de un cine anclado en la realidad que hace el cineasta juega un papel importante la figura del actor. Para el director cántabro, en el recurrente y plural debate sobre literatura y cine el componente decisivo es la presencia física del actor, hasta el punto de considerarla un fenómeno -en el sentido kantianoprevio al lenguaje cinematográfico ${ }^{5}$. Además de escribir los guiones pensando en actores concretos para la construcción de los personajes y rechazar un diseño abstracto, considera que el cuerpo otorga una materialidad y una conexión con la realidad viva al constructo -nunca es la cosa en sí, siempre un significante- que en todo caso es un largometraje: "El cuerpo del actor viene de afuera, del mundo real. La película solo le comparte" (Gutiérrez Aragón, 2004, 32). Esta consideración la realiza desde sus recuerdos de infancia donde las películas vienen identificadas (o remiten a) por los actores: "El primer conocimiento de la película era -y es- un conocimiento carnal, la cara y el cuerpo del actor o la actriz" (Gutiérrez Aragón, 2015, 24).

Pero no es el realismo más directo o el naturalismo lo que interesa al cineasta, incluso lo rechaza en cuanto "La representación de la realidad es a menudo frágil, desprovista de defensa ante los empujones de la realidad manipulada. El realismo es un conjunto de reglas sociales, impuestas normalmente por la clase dominante.” y concluye con firmeza: "El realismo tiene más que ver con la ideología que con la realidad" (Gutiérrez Aragón 2004, 30). De hecho estas pelícu- las siempre son propensas al apunte de diálogo, al detalle de ambientación o al fleco narrativo que amueblen su narración realista con elementos esperpénticos, distorsionantes, inesperados, fantasiosos, surrealistas o mágicos que otorgan a la película un espesor semántico y una ambición artística. Me refiero la escena de bestialismo o a la mitología de El corazón del bosque; al mago Chessman, los tíos judíos o la prueba iniciática de Maravillas; a la sesión de hipnosis y el cuento de hadas de Sonámbulos; al toro que irrumpe en la boda en Demonios en el jardín; a la virgen en el árbol de Feroz; o a la abuela adivinadora de La mitad del cielo. En otras ocasiones introduce un relato de segundo orden como el sueño o teatro en el cine (Sonámbulos, Maravillas) con personajes espectrales, que trascienden la realidad histórica; o devenidos personajes, como los del plató de televisión con la representación del Tenorio en La noche más hermosa.

La cámara (el cine) se revela, entonces, como un instrumento para conjurar la realidad por la vía de trascenderla mediante la imaginación al tiempo que, amplificándola, la muestra con mayor elocuencia: "Descubrir que podía soportar la realidad gracias a poder filmarla, me llenó de contento. Y la responsabilidad y el temblor se sobreimpresionaron en el mismo deseo impetuoso de gozar y conocer. El cine desvela la realidad. Pero la transparenta ante nuestros ojos entrecortada por el montaje, actuada, encarnada. La realidad aparece sobrestimada. (La cámara puede registrar por su cuenta, de manera automática. Eso nos hace pensar que lo que registra es real, inequívocamente real).” (Gutiérrez Aragón 2004, 30). Por tanto, la herramienta cine es una eficaz forma de aproximación crítica y plural a lo real, pues permite la doble perspectiva de alejamiento para trascenderla o de cercanía para tomar

\footnotetext{
5 "Lo que diferencia y separa a la vez al cine de la literatura es el cuerpo. La imagen del cuerpo está en el relato cinematográfico antes que la narración y el montaje, antes que el tiempo, antes que los planos y las secuencias. Antes que el lenguaje. La imagen de una película no es una imagen temporalizada, sino encarnada." (Gutiérrez Aragón, 2004, 31). Sobre la diferencia entre el actor de cine y teatro véase Gutiérrez Aragón $(2015,18)$.
} 
conciencia de ella en toda su complejidad.

Dos títulos resultan ejemplares en mostrar esta peculiar y plural dialéctica realidad/ficción, tan presente en toda la filmografía de este director: Sonámbulos y Maravillas. En la segunda se explicita con la inversión de papeles en los personajes (Maravillas/padre, Pirri/confesor, Juez/ delincuente), las teatralizaciones y representaciones (espectáculo de ilusionismo sobre la pena de muerte de Chessman, simulación de venta en grandes almacenes, quema catártica de las revistas pornográficas, ceremonia de rito judío, monólogo de La vida es sueño), y figuras como la del fotógrafo que desea una identidad postiza (quiere ser judío e inventa falsos recuerdos) y que, en cuanto fabricante de imágenes, posee el don de crear una realidad alternativa. Sonámbulos se vale de la literatura (los cuentos de hadas y las obras de teatro) para explorar esta dialéctica de realidad y ficción. Teatro es lo que hace que hace Ana cuando su hijo la ve llorar y retorcerse de dolor auténtico; como teatro parece la inversión de papeles entre estos dos personajes cuando es el hijo quien lee un cuento a su madre. La deliberada ambigüedad y/o confusión entre realidad y ficción resulta muy evidente, además de sugestiva, en secuencias como la hipnosis a que Ana es sometida por Norman, que tiene lugar en el teatro, con lo que el espectador no sabe si forma parte de una representación o no; o con estos mismos dos personajes en el momento de la psicoterapia y experimentación de orgasmo por Ana dormida delante de la enfermera Fátima. $\mathrm{El}$ enorme armario de tres cuerpos con espejos, que aparece en varios lugares (biblioteca, hogar y teatro), funciona como espejo de la Alicia de Lewis Carroll para comunicar, con lógica mágica, espacios diversos y, de ese modo, plasmar los mecanismos rizomáticos y la narrativa no lineal del relato. De igual modo, la opción por darles a los personajes los nombres auténticos de los actores, incluido el Ana Cuesta de la actriz Ana Belén, abunda en esta perspectiva de ruptura de la frontera entre realidad y ficción.

En consecuencia, el realismo queda muy matizado por esas distorsiones y huidas que pro- porcionan al cine de Gutiérrez Aragón una notable cualidad poética, pues, como señala Molina Foix "Lo especial del cine de Gutierrez Aragón, sin embargo, es que sus cuentos oníricos también resisten la luz diurna, y nos despiertan a la realidad inmediata, pues lo real se articula en su cine al modo fantástico, siempre que entendamos la fantasía como la define Coleridge en su Biographia Literaria: 'La fantasía no es otra cosa que una forma de la memoria, emancipada del orden del espacio y el tiempo" $(2003,17)$.

Esta particular vertebración entre realidad y ficción tiene que ver con la naturaleza del propio dispositivo cinematográfico, del cine en cuanto maquinaria de significación, según viene considerada por la teoría psicoanalítica del cine (Metz y Baudry) y fenomenológica (Morin), de suerte que la filmación de algo ya supone su ficcionalización. Así lo considera el propio cineasta: "Siempre he tenido la impresión de que, en el cine, presentar un sueño como tal puede ser redundante, porque la imagen cinematográfica es ya de por sí un poco onírica. La sintaxis del cine es como la de los sueños: entras en una habitación y, casi inmediatamente después, ya estás en la calle, sin ningún intermedio y sin transición. En el cine hay una manera de contar los sueños que, al hacerlos tomar una forma realista, los hace aparecer como si fueran pesadillas. Ahora bien, aunque el cine puede contarlo todo, sin embargo no puede contar un sueño, porque él mismo es sueño" (en F. Heredero, 1998b, 84).

En coherencia con esta consideración del carácter "onírico" del cinematógrafo, de la semejanza entre la sintaxis del cine y la de los sueños, el cineasta se vale de la estructura del cuento como esquema narrador para sus historias, que descubre de forma intuitiva desde su corto de prácticas Hansel y Gretel (Gregori, 2009, 918), pero ello no predispone necesariamente al desarrollo de la vertiente más fantasiosa o a la fabulación que le aleje del realismo, pues considera que "si hubiera una unidad narrativa, un metro-patrón narrativo, lo mismo de la novela que del cine, éste sería el cuento y, más concretamente el cuento maravilloso. El cuento subyace en todas las 
demás narraciones, porque habla de las pasiones elementales, que se dan siempre en el ser humano" (en F. Heredero, 1998b, 41). Así, hay que hacer notar cómo la fábula se despliega y llega a vertebrar todo el relato en Feroz, lo que inevitablemente la convierte en alegoría, por más que el cineasta se resista a desentrañar la metáfora o a lecturas lógicas que establezcan una relación de significante-significado precisa. En otros casos, como en Camada negra, bajo el realismo de personajes y situaciones subyace una estructura con el esquema narrativo y las funciones actanciales del cuento: el príncipe (Tatín), la princesa a conquistar (Rosa), la madrastra, las pruebas iniciáticas, el castillo del ogro... (F. Heredero, 1998a, 39); o se vale de la narración oral o la lectura de un cuento dentro del filme, como en Sonámbulos.

\section{MEMORIA FAMILIAR $Y$ ESPACIOS DE LA INFANCIA}

La citada primera dimensión de la realidad del cine de Gutiérrez Aragón está referida a un ámbito más personal y sensorial-afectivo, básicamente situado en el marco espaciotemporal de la vida familiar en la niñez. La infancia del cineasta es claramente identificable con la del niño enfermo de Demonios en el jardín, centro de atención de las mujeres de una casa grande. En varios lugares (Gutiérrez Aragón, 2004 y 2015, y Triunfo $n^{0}$ 17, 1982; F. Heredero 2004, 13-16) ha sido evocada esa infancia en un contexto familiar donde predominan la sobreprotección de las mujeres, la herencia cubana y el contacto con la Naturaleza de animales y espacios de montaña y bosque.

En la memoria familiar adquieren protagonismo las comidas que cohesionan a las familias, reforzando lazos y dependencias, o estimulan la gula, como las sopas de ajo y pimentón de Habla, mudita, el almuerzo de los guerrilleros de Cristo Rey presidido por la matriarca en Camada negra, las lentejas que repudia Ana en Sonámbulos, la leche de vaca para sobrevivir como animales sin destetar en El corazón del bosque, los garbanzos de Fuentesaúco o el arroz de Calasparra citados en Demonios en el jardín, la casquería fina y el arroz con leche del falangista de La mitad del cielo... Aunque las comidas adquieren diversas significaciones como, entre otros, ha estudiado Castellani (1987), su presencia otorga materialidad -el olor y el sabor que el medio cine no posee- a películas en las que el cineasta también valora la presencia del cuerpo del actor.

La Naturaleza se circunscribe, en este cine, a la montaña y al medio rural como espacios de infancia y crecimiento, de incomunicación y pugna por el conocimiento; de seres furtivos, incomprendidos o etiquetados como salvajes, desde la joven muda al hombre-oso pasando por el guerrillero; lugares donde se manifiesta con espontaneidad la cualidad primitiva del ser humano, que adquieren la condición de refugio pero también espacios germinales de luchadores, como la protagonista de La mitad del cielo. En el fondo, esa Naturaleza como espacio dramático del cine sirve para plasmar reflexiones de fondo sobre la condición humana; así, se pone en escena la dialéctica natura/cultura mediante el encuentro entre personajes urbanos y rurales como en Habla, mudita y en El corazón del bosque en las que "el medio natural determina a sus personajes, sobre todo a los más primitivos. Como tengo una concepción del cine muy material, esa dimensión de la película, que pone en relación el medio físico y la condición moral de los personajes" (en F. Heredero $1998 \mathrm{~b}, 65)$.

El bosque fantasmal guarda todos los secretos tras la niebla que empaña la vista e impide la certeza del conocimiento, por ello los humanos en el bosque tienen más miedo, devienen más violentos y son más frágiles. Ninguna ingenuidad rousseauniana en la mirada del cineasta a esa Naturaleza tan fértil como áspera, tan nutritiva como devastadora, pues los personajes se sitúan como esforzados supervivientes y, lejos de todo paraíso, está bastante presente la violencia y el aislamiento. El bosque es también un espacio mitológico -mejor, quizá, mitopoiético- porque genera leyendas y desarrolla el alma mágica de los humanos quienes, en no pocas ocasiones, se ven insertos en el medio natural de forma directa, en continuidad con animales y plantas, sin 
mediaciones culturales, como la pastora de $\mathrm{Ha}$ bla, mudita.

\section{LA DIMENSIÓN DEL CONTEXTO HISTÓRICO Y POLÍTICO}

La otra dimensión de la realidad atendida por esta filmografía es el contexto histórico y político, con el marco dominante de la herencia del franquismo y las incertidumbres de la transición a la democracia. Gutiérrez Aragón no hace cine histórico -en ese período del segundo lustro de los setenta en que abunda la revisión de la Historia española reciente- ni busca deliberadamente la coartada histórica para un cine con discurso político. Aunque ello no significa crear argumentos refractarios al contexto español que le ha tocado vivir, desde la España de posguerra de la infancia a la contestación antifranquista de estudiante o las tensiones contemporáneas a su cine que tienen lugar en la Transición.

Camada negra, Sonámbulos y El corazón del bosque forman un tríptico de análisis histórico y sociopolítico sobre la herencia franquista que llega a la España de la Transición. El tríptico parte del presente para abundar en las raíces del pasado: la primera entrega sitúa la historia en el momento del filme (1977), Sonámbulos ubica la acción poco más de un lustro atrás, en los años del proceso de Burgos (diciembre de 1970) y El corazón del bosque se remonta a la guerrilla de los años cincuenta. Previamente, junto a José Luis Borau, ha escrito Furtivos (1975) en la misma línea de análisis del franquismo, que bien puede situarse como un prólogo de este tríptico; y, poco después, vuelve sobre el período en $D e$ monios en el jardín y en La mitad del cielo.

La guerrilla antifranquista en la posguerra es presentada desde su fracaso, cuando el PCE decide poner fin a la resistencia armada y enviar a un emisario para que disuada al último emboscado, El Andarín. El corazón del bosque -que nunca fue una adaptación de El corazón de las tinieblas de Joseph Conrad ni se inspiró en ella: simplemente se comprueba una vez hecha cierto parecido en el argumento- se nutre de la historia legendaria y mitologizada de "los que se echaron al monte" 6 en la Cantabria de la infancia del director. Se subraya la solidaridad (o miedo) de la gente de los pueblos con los huidos, la crueldad de las fuerzas del orden y el deterioro físico y moral/político que viven los guerrilleros conforme pasa el tiempo, cada vez más aislados. Pero no hay heroísmo ni épica alguna: menos aún en el comisario político que asesina al resistente por propia iniciativa o por orden del partido.

En los últimos años del franquismo está ambientada Sonámbulos, uno de los filmes con mayor desarrollo de su vertiente fantástica y metafórica, y por ello susceptible de interpretaciones diversas. La protagonista es una militante antifranquista que delata a los suyos a la policía, lo que hace de ella paradigma de la figura del traidor; y se ha visto en la película la carta de dimisión del cineasta como militante del PCE. El personaje de Ana posee la dicotomía del prototipo héroe/traidor, pero lo más interesante es el proceso de desencantamiento que experimenta al perder el conocimiento (le roban el libro) y la conciencia/voluntad (enfermedad mental que le deja a merced de los otros), lo que acaba por explicar la delación a la policía de la actividad del grupo antifranquista. Es decir, en 1978, en el momento de la renuncia a ideales revolucionarios por parte de la izquierda que tiene que asumir con pesar que el régimen termina porque Franco muere en la cama, momento de constatación de la imposibilidad de un cambio político más radical, de la "democracia establecida" (Aranguren) y del desencanto, el director echa la vista atrás

\footnotetext{
6 Este es el título del libro de Isidro Cicero sobre el maquis en Cantabria, publicado en 1977 por Editorial Popular.

7 Este es el testimonio: "Se trataba de una película muy comprometida porque los guerrilleros [de Cristo Rey, el grupo de extrema derecha retratado] que salían en la pantalla también estaban en la realidad. Tanto es así que lo cierto es que atacaron el cine, pusieron una bomba, luego atacaron a los del Café Comercial que estaba al lado del cine Luchana, donde se estrenó y que no tenían ninguna culpa. Pero evidentemente, causó muchos problemas y dejó de estrenarse en muchos puntos de España porque daba miedo. Pero yo creo que es una película que había que hacer porque alguien tenía que realizar una película sobre los guerrilleros de Cristo Rey." (Gregori, 2009, 919).
} 
y reflexiona sobre las impotencias y ambigüedades de la lucha antifranquista.

Del presente de 1977, el año de la legalización del PCE y de las elecciones generales que dan lugar a las Cortes constituyentes, da cuenta $\mathrm{Ca}$ mada negra, con la historia de un grupo fascista militante en sembrar el pánico y entorpecer el acceso a la democracia. El director es consciente de que se trata de una película necesaria de denuncia política, lo que conlleva problemas en el estreno7; pero ello no supone localismo alguno, pues lleva su discurso a las raíces antropológicas y psicosociales, lo que otorga al filme un valor más universal del análisis del fascismo al abundar en la inmadurez psicológica, el complejo de Edipo, las deficiencias de autoestima y hasta la pulsión necrófila del ser humano alimentada por las frustraciones que puede proporcionar un determinado contexto familiar e histórico. Pues el héroe/traidor viene amamantado por la familia matriarcal autoritaria, la religiosidad gregaria y la connivencia del Estado (aún franquista).

Fuera de la trilogía, tanto en Demonios en el jardín como en La mitad del cielo hay una reflexión sobre el franquismo desde la memoria personal: más que el análisis histórico o político interesa la dimensión sociológica o la crítica costumbrista. Así, en la primera el falangista Juan es un fracasado que trabaja como camarero del Caudillo, él y su hermano tiran de pistola con prepotencia y la familia adicta al régimen engaña lo que puede con el estraperlo; frente a ellos, Ángela -que representa la España derrotada- es la única inocente que tiene que sobrevivir y soportar que maleduquen a su hijo o la ignominia de un matrimonio de conveniencia. La desmitificación del padre por parte del niño -del uniforme de guardia de Franco al de camarero- viene a ser, también, una desmitificación de la retórica visual de los fascismos, legitimados con uniformes, desfiles y decorados que consiguen, gracias a esa fascinación visual, la adhesión emocional por encima de toda ideología; como ha explicado el director "es un poco equivalente a lo que sentimos nosotros, niños de derechas, cuando vimos quién era Franco. No nos hicimos anti- franquistas por una cuestión de izquierdas, sino cuando nos dimos cuenta de que Franco nos parecía bajito. Y se acabó el mito" (La Vanguardia, 23-10-1982). El irónico desenlace, con la foto de falsa armonía familiar (con Juan disimulando la herida del tiro producido por Ana despechada, pero del que se autoinculpa su hermano: mentira sobre mentira), ejemplifica la perspectiva que el director ha elegido para toda la película. Porque, a fin de cuentas y por debajo de la anécdota argumental, Demonios en el jardín es un retrato de un tiempo de falsedades, pues con la excepción de Ángela, todos los personajes se aprovechan del engaño para mejorar su modo de vida, satisfacer sus apetencias o cultivar su ego.

En La mitad del cielo, Gutiérrez Aragón maneja distintos registros en un relato que ofrece la fascinación del personaje protagonista -que, prácticamente, no desaparece de la pantalla- con una de las mujeres más fuertes del cine español, pero que tiene algo de fábula, sátira del cambio de falangistas por tecnócratas del Opus Dei en el franquismo, drama de enredo, crónica familiar y hasta comedia costumbrista. El carácter de crónica histórica tiene mucho interés, con en el retrato de "un mundo habitado por viejos (y ahora dignos) falangistas derrotados, mercados fabulosos, tecnócratas en ascenso, restaurantes de lujo, arribistas de nuevo cuño, políticos corruptos y sueños de futuro" (Heredero, 1998, 100).

Como no podía ser de otro modo, estas películas se hacen eco de la realidad social más contemporánea, no sólo en las tensiones ${ }^{8}$ propias

\footnotetext{
8 El cineasta advierte explícitamente esa complejidad al señalar "Aquí jugué a fondo con los contrastes entre unas historias y otras, con el choque entre imágenes de distinta naturaleza, con las paradojas del comportamiento y hasta con varios tipos de hilos narrativos que se cruzan o que se superponen. (...) Me interesaba explorar las contradicciones de la realidad, la contraposición entre personajes, la visión en negativo fotográfico de las relaciones paterno-filiales, los sinsentidos de nuestro comportamiento social, el carácter intercambiable de las convenciones que sostienen nuestros pensamientos, y todo ello desde una perspectiva humorística que pretendía tener un cierto sentido crítico o, al menos, irónico" (en F. Heredero, 1998b, 79).

9 Véase al respecto el artículo del profesor Gérard Imbert en este
} mismo número de Área Abierta 
del cambio político que tiene lugar en la Transición (Camada negra), sino también en diagnósticos sobre la actualidad al hilo de argumentos con otras preocupaciones. Es lo que sucede con Maravillas (1980), una obra compleja transida de múltiples tensiones ; y con La noche más hermosa (1984), con una historia de celos, infidelidades, sospechas e identidades sexuales inciertas.

En Maravillas destaca la cuestión de la delincuencia juvenil, que en esos años alcanza un fuerte impacto en la sociedad española por el elevado número de delitos que se contabilizan, la mayoría asociados al tráfico y consumo de drogas. Esta realidad aparece reflejada de forma muy directa y rica en el ciclo del "cine quinqui" $\tan$ recurrente en esos años, con películas de José Antonio de la Loma y Eloy de la Iglesia. El propio Pirri (José Luis Fernández Eguía), modelo de actor natural (Gutiérrez Aragón, 2015, 9-99), que había debutado en el cine poco antes -en Navajeros (1980)- procede de una familia desestructurada, tiene una carrera como delincuente y fallece de sobredosis de heroína con 23 años en 1988. En el espectáculo de ilusionismo sobre Chessman hay eco de la reivindicación de la supresión de la pena de muerte que, poco antes, habían realizado amplios sectores de la izquierda española -sobre todo porque se identificaba mucho con la máxima represión del franquismo- y que se había logrado con la aprobación de la Constitución de 1978, aunque con la salvedad del ámbito militar en tiempo de guerra. Por su parte, en La noche más hermosa hay todo un diagnóstico de las insuficiencias de la democracia establecida con la crítica a la manipulación de la televisión pública y al cinismo de los responsables políticos imbuidos de los "nuevos valores" de la cultura del pelotazo. TVE aparece como metáfora hiperbólica de la sociedad española donde reina el caos, el partidismo y los intereses personales en la toma de decisiones.

\section{LA CONSTRUCCIÓN DE LOS PERSONAJES}

En este cine donde, como queda dicho, el actor proporciona realismo físico a las historias, la construcción de los personajes resulta central en todos los órdenes. Quizá la característica más notable de los personajes de esta filmografía sea su entidad moral o ideológica determinada por la adquisición del conocimiento (o las perversiones de la manipulación como des-conocimiento) y por el contexto histórico.

Hay historias que vienen vertebradas por procesos de aprendizaje o de relación educativa donde la adquisición del lenguaje es una herramienta de comunicación y, por consiguiente, de socialización ${ }^{10}$ : me refiero a Habla, mudita con la pastora sordomuda a quien el editor intenta enseñar a comunicarse y, por tanto, proporcionarle el don de la palabra; y a la metafórica del oso de Feroz que oculta a un humano dentro. En ellas, ese aprendizaje viene a subrayar el citado contraste natura/cultura, en cuanto cada uno de los medios conlleva unos valores, de manera que la inserción del sujeto en un determinado espacio social con unos valores políticos y morales concretos. La adquisición o el dominio del lenguaje como herramienta de comunicación es, también, condición para la inserción social y la participación en la comunidad; el silencio es la soledad, como se refleja en El corazón del bosque donde El Andarín deambula en un espacio poblado únicamente por los ruidos de las alimañas.

Como contraste, se muestra la perversión del adoctrinamiento que experimenta el adolescente de Camada negra en cuanto cachorro del fascismo que pasa una serie de pruebas, incluida la traición a la chica que le gusta. En una perspectiva próxima, pero de diferente tratamiento y entidad moral, puesto que el protagonismo recae sobre el sujeto del aprendizaje y el proceso se refiere más al ámbito intelectual, en Maravillas hay un relato iniciático al saber, un "cuento de conocimiento" o fábula sobre el crecimiento y la toma de conciencia de los corsés de la socie-

10 El director es muy consciente de la envergadura de la cuestión del lenguaje: "Si elegí la paradoja del lenguaje para dar cuerpo a estas reflexiones es porque el lenguaje, al ser una de las raíces de la cultura, lo sostiene todo: desde la literatura hasta la política, desde la religión hasta nuestras relaciones personales, domésticas y familiares" (en F. Heredero, 1998b, 66). 
dad y los roles asignados a cada uno. Pero la adquisición del conocimiento no lleva a una felicidad de la verdad sino a la lucidez de la miseria social. También en la maduración de Olvido ( $L a$ mitad del cielo) hay un proceso de acceso al conocimiento. Por su parte, la relación entre Norman y Ana (Sonámbulos) con las sesiones de psicoterapia se ubica, asimismo, en esa dimensión de adoctrinamiento en el que no está muy claro que posea un carácter liberador.

El tema del héroe y el traidor es recurrente en la filmografía de Gutiérrez Aragón y aparece ya en su cortometraje de práctica del segundo año de la Escuela Oficial de Cine Nana para dormir a un héroe (1967). Más allá de los estereotipos y los roles establecidos en orden al mecanismo funcional de la trama, le interesa la paradoja del héroe rebelde frente a su destino o a lo que la sociedad espera de él, de suerte que se convierte en un héroe negativo. También resulta original su visión de la figura del traidor, que no equivale al villano o a un antagonista poseído por contravalores, sino a quien se enfrenta al destino desde fuertes convicciones sin ser comprendido por la sociedad, y para hacerlo tiene que ir contracorriente. Pero "Al fin y al cabo, los traidores son los artífices de que haya paz entre los seres humanos" (F. Heredero, 1998b, 59) y pone los ejemplos de líderes políticos que traicionaron las dictaduras en las que llegaron al poder máximo para desmontarlas, como el rey Juan Carlos, Adolfo Suárez o Mijail Gorvachov. Así, el comisario Juan de El corazón del bosque se comporta como pacificador en su traición al Andarín o el militante del grupo fascista de Camada negra que es confidente de la policía.

La mostración de las debilidades del traidor o de las manipulaciones en los procesos de aprendizaje probablemente tiene que ver con la ausencia de la figura paterna en cuanto autoridad, referencia o modelo educativo que sirva para la maduración de las personas en crecimiento. En varios títulos es notable la ausencia de esa figura, lo que siempre conlleva algún tipo de conflicto, sea el simbólico "matar al padre" de Ana (Sonámbulos), sea la desmitificación, como en niño de Demonios en el jardín, o la puesta en cuestión de las normas/valores educativos, como Olvido de La mitad del cielo; o su relegación a un segundo plano, como lamenta la protagonista de $\mathrm{Ma}$ ravillas, repitiendo que su padre no se ocupaba mucho de ella y donde se invierten los roles de educador/educando.

\section{CONCLUSIONES}

Llegados a este punto, con la provisionalidad y prudencia que han de presidir la reflexión académica acerca de la creación artística en general y la de un autor tan escurridizo como Gutiérrez Aragón en particular podríamos establecer algunas conclusiones. A mi juicio, este cine puede comprenderse según la clave que enuncia el título de estas páginas: la dialéctica entre la realidad histórica -social, biográfica- más documentada y una fabulación que recrea esa realidad desde la memoria personal según las preocupaciones de a) los procesos de aprendizaje y adquisición del conocimiento; y b) del rol desempeñado en la situación histórica de cada momento y del compromiso moral subsiguiente. En esa dialéctica sobresalen los siguientes aspectos:

a. El espacio físico de la infancia del cineasta (el medio rural y el bosque en particular) adquiere un fuerte protagonismo en varios títulos.

b. La memoria personal se erige en filtro básico de las recreaciones y las fabulaciones, de manera que es posible rastrear no pocos componentes de la biografía de la infancia del cineasta y de su contexto familiar.

c. El pasado del franquismo y el presente de la Transición a la democracia son el marco de actuación de personajes complejos y contradictorios en su supervivencia en un contexto sociopolítico hostil.

d. En varios de los personajes protagonistas el devenir existencial se concreta en el proceso de aprendizaje/adiestramiento y la adquisición del conocimiento en orden a la construcción moral y/o ideológica de la personalidad. 


\section{BIBLIOGRAFÍA}

ANTOLíN, Matías (1983), Manuel Gutiérrez Aragón, Madrid, Sombras Chinescas.

CASTELLANI, Jean-Pierre (1987), "La nourriture chez Manuel Gutiérrez Aragón: représentation et role dans 'Demonios en el jardín'", Hispanistica XX, no 5, Université de Bourgogne.

GÓMEZ, Agustín (2013). "El bosque físico y metafísico en el corazón de Manuel Gutiérrez Aragón", en Paisajes del cine rural español (Pedro Poyato, ed.), Córdoba, Diputación de Córdoba, pp. 77-104.

GREGORI, Antonio (2009), El cine español según sus directores, Madrid, Cátedra.

GUTIÉRREZ ARAGÓN, Manuel (2004), Jardín de deseos, discurso de ingreso en la Real Academia de Bellas Artes de San Fernando, Madrid; disponible en www. realacademiabellasartessanfernando.com.

(2008), Películas imposibles, Madrid, Ocho y Medio.

(2015), A los actores, Barcelona, Anagrama.

HEREDERO, Carlos F. (1998a), Cuentos de magia y conocimiento. El cine de Manuel Gutiérrez Aragón, Madrid, Alta Films.

(1998b), Historias de vida y de ficción. El cine según Manuel Gutiérrez Aragón, Huesca, Festival de Cine.

(2004), Manuel Gutiérrez Aragón. Las fábulas del cronista, Madrid, Iberautor y Ocho y Medio.

JUAN PAYÁN, Miguel y López, José Luis (1985), Manuel Gutiérrez Aragón, Madrid, Ed. JC.

MARTÍNEZ TORRES, Augusto (1985), Conversaciones con Manuel Gutiérrez Aragón, Madrid, Fundamentos.

MOLINA FOIX, Vicente (2003), Manuel Gutiérrez Aragón, Madrid, Cátedra.

SÁNCHEZ NORIEGA, José Luis (2005), "Humor y utopía en los Quijotes de Manuel Gutiérrez Aragón", Boletín de la Biblioteca de Menéndez Pelayo, ISSN 0006-1646, Año 81, pp. 493-515.

(ed., 2014), Filmando el cambio social. Las películas de la Transición, Barcelona, Laertes.

(2015), "Entre lo que se es y no se es", Cine para leer, http://www.cineparaleer.com/libros/item/1776-entre-loque-se-es-y-no-se-es (visitado 2-10-2015).

VALLEJO CHANAL, Antonio (2000), Soñar el cine. El cine de Manuel Gutiérrez Aragón, Cartagena, Semana de Cine Naval y del Mar. 